\title{
EV71 可感染幼龄中缅树鼠
}

\author{
王文广，黄晓燕，徐 娟，孙晓梅，代解杰*，李琦涵 ${ }^{*}$ \\ (中国医学科学院/北京协和医学院医学生物学研究所 全国医学灵长类研究中心, 云南 昆明 650118)
}

\begin{abstract}
摘要: 树鼠是灵长类动物的近亲, 且具有体型小、繁殖周期短、饲养管理成本低等优点, 长期以来被认为有 望替代灵长类动物用于人类疾病的动物模型研究。该文研究了肠道病毒 EV71 对幼年中缅树舄的感染特点, 探索 建立 EV71 感染树䳔动物模型及替代灵长类动物的可行性。实验分别采用灌胃、滴鼻和尾静脉注射 3 种方式, 感 染 3 月龄树鼠, 定期观察动物临床症状和血常规变化和定期采集血液和粪便样品, 并使用中和抗体试验、 reverse transcription-PCR (RT-PCR)和 Real-Time PCR 等技术, 检测相关样品中和抗体效价、病毒核酸及载量变化。结合 组织病理学检查, 分析感染病变特点。研究结果发现, 实验组树獡体温在第 4 天前后开始升高, 白细胞、淋巴细 胞也有类似趋势; 3 种攻毒方式均可检测到病毒载量, 峰值出现在第 10 天前后, 灌胃途径尤为明显, 血清的最大中 和抗体效价为 $1: 16$ 。感染 EV71 病毒的树舄 2 周左右出现急性松弛性瘫疾, 大体解剖发现伴有尿潴留症状, 组织 病理学检查发现在脑、肺、肠、脾脏、肾脏等部位发生病变。结果表明, EV71 病毒通过灌胃、滴鼻和静脉注射 3 种方式均可以感染中缅树鼠, 并使之出现神经系统及相关病变, 该实验为将来研究 EV71 感染树䳔致病机理、建立 手足口病树鼣动物模型奠定了理论基础。
\end{abstract}

关键词: 手足口病; EV71; 中缅树鼣; 动物模型

中图分类号：Q95-33; R373; Q959.837 文献标志码：A＼cjkstart文章编号：0254-5853-(2012)01-0007-07

\section{Experimental studies on infant Tupaia belangeri chineses with EV71 infection}

\author{
WANG Wen-Guang, HUANG Xiao-Yan, XU Juan, SUN Xiao-Mei, DAI Jie-Jie*, LI Qi-Han ${ }^{*}$ \\ (The Medical Primate Research Center of China, Institute of Medical Biology, the Chinese Academy of Medical Science and \\ Peking Union Medical College, Kunming 650118, China)
}

\begin{abstract}
Tupaia belangeri are small mammals with a squirrel-like appearance; they were formerly classified under the primates order despite the lack of derived features characteristic of primates. Given that $T$. belangeri are easy to raise, cheap to maintain, and have a small body size, a high reproductive rate, and close affinity to primates, these animals would be used as an alternative to primates in biomedical research. Three-month old $T$. belangeri chineses were infected with enterovirus 71 (EV71) via three different routes, namely, oral administration, nasal dripping, and tail intravenous injection, to study the infection in infant $T$. belangeri and find a feasible scheme to make them an ideal animal model of EV71 in place of primates. Daily activities were regularly observed, body temperatures were measured, and blood tests were conducted. Blood and fecal samples were regularly collected. The infection was examined via the neutralizing antibody test, reverse transcription polymerase chain reaction (RT-PCR), Real-Time PCR, and pathological analysis. The temperature, as well as the white blood cell count and the number of lymphocytes, increased four days after infection. Virus loads were determined in all three groups, and the peak appeared on, before, or after the tenth day, respectively. Thus, oral administration proved to be the best route. The highest serum antibody titer obtained was 1:16. Acute paralysis with urinary retention manifested after about two weeks, and pathological changes were observed in the brain, heart, lung, spleen, kidney, and other tissues. In conclusion, T. belangeri chineses can infected with EV71 via oral administration, nasal dripping, and tail intravenous injection. Therefore, T. belangeri are potential EV71 animal models for further studies on the mechanism of pathogenesis or vaccine evaluation.
\end{abstract}

收稿日期: 2011-10-27; 接受日期: 2012-01-10

基金项目: “十一五”国家科技支撑计划项目 (2009BAI83B02; 2011BAI15B01)；云南省科技基础条件平台建设计划项目(2006PT07-2); 国家“973” 计划项目(2011CB504903); 国家自然科学基金(81171573); 云南省应用基础研究计划面上项目(2011FB116)

*通信作者(Corresponding author), E-mail: djj@imbcams.com.cn; imbcams.lq@gmail.com

第一作者简介：王文广，男，硕士研究生，研究方向：人类疾病动物模型研究; Email:windgone@imbcams.com.cn 
Key words: Hand-foot-mouth disease; EV71 virus; Tupaia belangeri chineses; Animal model

手足口病是由肠道病毒引起的传染病, EV71 是手足口病的主要致病原之一, 可使患者并发中枢 神经系统疾病和相关心肺功能衰竭等临床症状, 严 重威胁世界各地婴、幼儿的生命健康, 目前尚无有 效药物或疫苗。建立合适的动物模型是深入基础研 究和进行药物评价的关键之一。国内外已有 EV71 感染小鼠的报道, 先后建立了乳鼠(Lin et al, 2009) 和成年小鼠(Duo et al, 2009)的感染模型, 但乳鼠个 体过小, 不便操作且发病期太短; 成年小鼠不易感 染, 无法满足药物或疫苗的评价工作需要。非人灵 长类动物模型较有前景。Nagata et al (2004)通过静 脉注射建立了 EV71 感染猕猴的模型, 呈现与人脑 炎类似的临床体征与神经病理。Liu et al (2011)已成 功使肾猴感染 EV71, 并建立了较为可行的动物模 型评价标准。灵长类动物模型固然理想, 然而成本 昂贵, 研究周期长, 动物伦理审查严格。树鼠作为 一种新开发的实验动物, 进化上接近灵长类(Sargis, 2004), 生理代谢与人类有诸多相似之处, 具有较大 的科研潜力, 再加上饲养方便、成本低廉, 具备建 立理想动物模型的先天优势。近年来的研究成果表 明, 树鼠对多种人类常见疾病具有再现的潜质, 人 们已经较成功地建立了肝炎等多种病毒感染性疾 病模型(Wang et al, 2010)。Wang et al (2011)报道野 生中缅树鼠携带有肠道病毒中的柯萨奇病毒, 提示 树獡可能对肠道病毒易感。本文研究了 EV71 对中 缅树鼠的感染能力, 探索建立其动物模型的可行性。

\section{1 材料和方法}

\section{1 材料}

1.1.1 实验动物 经人工繁育的 $\mathrm{F} 1$ 代 3 月龄中缅 树獡 14 只, 雌雄各半, 体重 $(120 \pm 20) \mathrm{g}$, 来自中国 医学科学院医学生物学研究所医学灵长类中心。

1.1.2 毒株 EV71 标准毒株(FY-23), 由中国医学 科学院医学生物学研究所病毒免疫室分离并馈赠。

Vero 细胞培养, 滴度测定为 $8.5 \times 10^{8} \mathrm{TCID}_{50} / \mathrm{mL}$ 。

1.1.3 仪器 动物血球分析仪 HEMAVET 950、欧 姆龙MC-140 电子体温计、日立台式离心机 CT15RE、 MyCycler PCR 仪、CFX 96 实时定量 PCR 仪、 ND-1000 微量紫外可见分光光度计和 Thermo 二氧 化碳培养箱等仪器。
1.1.4 试 剂 Minimum essential medium (MEM) 液体培养基、标准新生牛血清(兰州民海生物工程有 限公司)、RNA 提取试剂 RNAiso Plus (大连宝生 物:D9108A)、逆转录试剂 RT Master Mix (大连宝生 物:DRR036A)、PCR 试剂 $2 \times$ GoldStar Taq MasterMix (北京康为世纪:CW0960)和实时定量 PCR 试剂 GoldStar TaqMan Mixture(北京康为世 纪:CW0932)等试剂, 以及引物探针均由大连宝生 物公司合成。

\section{2 方法}

1.2.1 动物分组 挑选 14 只三月龄健康树鼠, 雌 雄各半。动物随机分组: 灌胃组、滴鼻组和静脉注 射组, 每组 4 只, 雌雄各半, 另两只设对照组(表 1)。 本方案经医学生物学研究所动物伦理委员会审核 通过。

表 1 分组感染表

Tab. 1 Tupaia belangeri with EV71 infection in groups A-D

\begin{tabular}{cccc}
\hline $\begin{array}{c}\text { 组别 } \\
\text { Group }\end{array}$ & $\begin{array}{c}\text { 攻毒途径 } \\
\text { Route of infections }\end{array}$ & $\begin{array}{c}\text { 感染剂量 } \\
\text { Dose of infection } \\
\left(\mathrm{TCID}_{50}\right)\end{array}$ & $\begin{array}{c}\text { 动物编号数量 } \\
\text { Amount } \\
\text { (No.) }\end{array}$ \\
\hline A & 灌胃 Oral administration & $8.5 \times 10^{7}$ & $4(1 \sim 4$ 号 $)$ \\
B & 滴鼻 Nasal dripping & $8.5 \times 10^{7}$ & $4(5 \sim 8$ 号 $)$ \\
C & 静脉注射 Tail intravenous injection & $8.5 \times 10^{7}$ & $4(9 \sim 12$ 号 $)$ \\
D & 对照 Control & - & $2(13 \sim 14$ 号 $)$ \\
\hline
\end{tabular}

1.2.2 日常观察 攻毒后每天观察动物活动状况、 精神状态, 以及饮食、大便等。每天 9:00 测量记录 动物肛温, 保定动物待其处于平静状态, 使用欧姆 龙 MC-140 电子体温计测量记录动物肛温。

1.2.3 血样采集 攻毒前采尾静脉血做本底, 攻毒 后 $3 \mathrm{~d} 1$ 次, 每次采集 $0.6 \mathrm{~mL}$ 。先分取 $100 \mu \mathrm{L}$ 血样 用乙二胺四乙酸二钠(EDTA-2Na)抗凝做血常规检 测, 其余分离血清 $-20{ }^{\circ} \mathrm{C}$ 冻存备用。

1.2.4 血常规检测 根据上述血样采集方案制备 EDTA-2Na 抗凝血, 按照动物血球分析仪 HEMAVET 950 操作说明进行血细胞的测定。

1.2.5 粪便采集 从攻毒前 $1 \mathrm{~d}$ 开始, 每天 8:30 采 集粪便, 取样 1 2 $\mathrm{g}$ 。采集粪便用添加双抗(青霉素 和链霉素)的磷酸盐缓冲液(PBS)混制成 $20 \%$ 悬液, 冻融处理后离心取上清 $-20{ }^{\circ} \mathrm{C}$ 冻存备用。

1.2.6 抗体中和试验 待测血清样品统一 $56{ }^{\circ} \mathrm{C}$ 灭 活 $30 \mathrm{~min}$, 用 MEM 细胞培养液从 2 倍、4 倍系列 
稀释到 32 倍。于 96 孔板中, 分别将各梯度稀释样 品 $50 \mu \mathrm{L}$, 与等体积 $100 \mathrm{TCID}_{50}$ 的 $\mathrm{EV} 7137{ }^{\circ} \mathrm{C}$ 中和 $2 \mathrm{~min}$, 平行 4 孔, 每块培养板均设血清、病毒和细 胞对照, 加入 Vero 细胞悬液 $100 \mu \mathrm{L}$, 细胞终浓度为 $2 \times 10^{5}$ 个 $/ \mathrm{mL}$, 于 $\mathrm{CO}_{2}$ 培养箱中 $37{ }^{\circ} \mathrm{C}$ 培养 $7 \mathrm{~d}$, 将 能使 $50 \%$ 细胞孔不产生病变的最高稀释度的倒数 定为该血清的中和效价。每次试验均设病毒回滴试 验, 且回滴结果在 $32 \sim 320 \mathrm{TCID}_{50}$ / 孔时, 试验判为 成立(Mao et al, 2010 )。

1.2.7 EV71 核酸检测 1) 应用 RNAiso Plus (TaKaRa:D9108A) 等试剂分别提取血清和粪便上 清中总 RNA, 使用 RT Master Mix 逆转录为 $c$ DNA。

2) 常规 PCR: 以逆转录的 CDNA 为模板, 反应 体系和反应条件按照北京康为世纪的 $2 \times$ GoldStar Taq MasterMix 试剂盒进行操作, 根据 EV71 FY-23 (GenBank:EU812515) 基因序列保守区设计引物。 上游引物 $\mathrm{EV} 71-\mathrm{S}(2369-2388)$ : 5'-GCAGCCCAAAAGAACTTCAC-3'; 下游引物 EV71-A(2 576-2 595): 5'-ATTTCAGCAGCTTGGAG $T G C-3^{\prime}$; PCR 产物长度 $226 \mathrm{bp}$ 。

3) Real-time PCR: 同样以逆转录的 cDNA 为模 板, 标准品定量稀释梯度为 $10^{7} 、 10^{6} 、 10^{5} 、 10^{4}$ 拷 贝 $/ \mu \mathrm{L}$ ，反应体系和反应条件按北京康为世纪的 GoldStar TaqMan Mixture 试剂盒进行操作, 根据 EV71 FY-23 (GenBank:EU812515) 基因序列保守区 设计引物探针。上游引物 EV71-F(2 828-2 848): 5'-CGCTTTGACGCAGAGTTCACT-3'; 下游引物 EV71-R (2 877-2 897): 5'-TTGGAGCAATTGTGGGA CGA-3'; 探针 EV71-P(2 849-2 870): 5'-FAM-TTGTT GCGTGCACACCCACCG-BHQ1-3'。

1.2.8 组织病理学检查 出现急症动物及时处死 解剖, 取出脑、肺、心、肠、脾、肾等相关组织器 官，中性福尔马林溶液固定，常规石蜡包埋， $2 \mu \mathrm{m}$ 切片, 苏木素-伊红(hematoxylin-eosin, HE)染色, 光镜下观察组织病理学变化。

\section{2 结 果}

\section{1 临床观察}

实验组树鼠在攻毒后 $3 \mathrm{~d}$ 开始出现黑褐色稀便, 1 周左右开始出现活动异常, 饮食下降, 跳跃活动 减少。体温监测显示, 3 组树舄均在第 4 天前后开始 上升，第 6 天前后达到最高，之后开始回落到正常 水平(图 1)。2 周后大于半数树鼣先后出现急性松弛
性瘫疾，蜷缩萎靡，树鼠后腿松弛拖拉，不能正常 活动，靠前腿拖行，精神极度萎靡，眼眶下陷，双 目呆滞。半数树鼣于 $18 \mathrm{~d}$ 前后死亡, 其中观察到灌 胃组的 4 号树鼠嘴角和前掌出现小疮疹(图 2)。

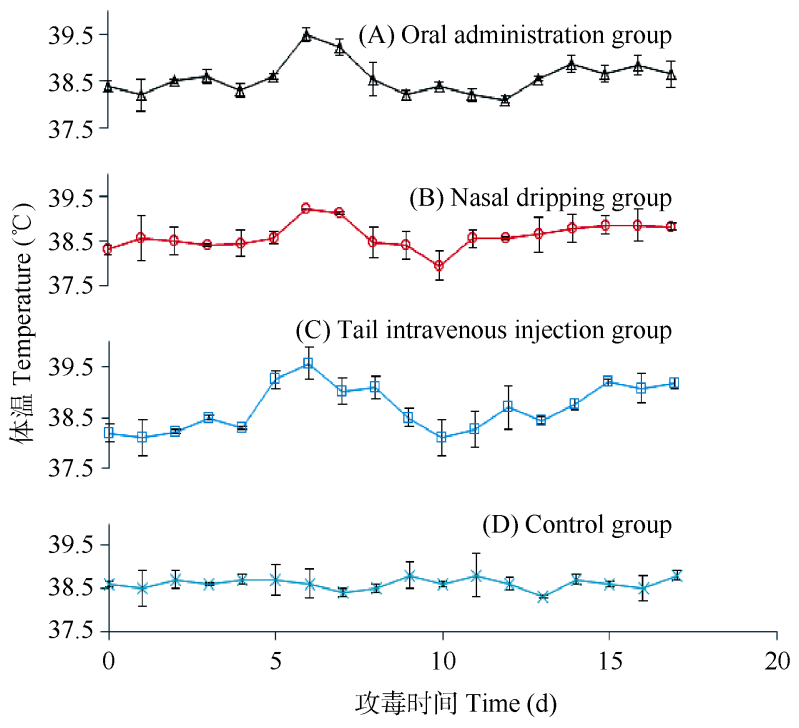

图 1 EV71 感染树獡体温变化趋势

Fig. 1 Changes in the body temperature of EV71 infected Tupaia belangeri

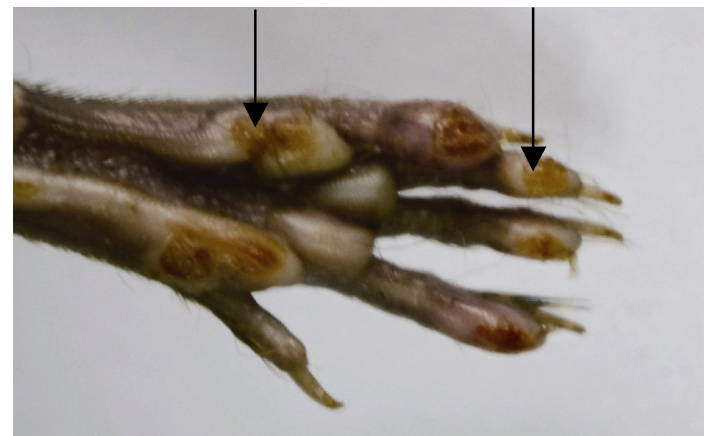

图 2 EV71 感染树鼠脚掌出现的小疮疹

Fig. 2 Small herpes in palm of EV71 infected Tupaia belangeri

\section{2 血常规检测}

血常规检测结果显示, 与对照组相比，实验组 树䳔白细胞(WBC)均呈现一个升降波动, 波动发生 在第 5 天到第 15 天之间，淋巴细胞(LYM)有相似的 变化趋势(图 3、图 4)。

\section{3 中和抗体试验}

抗体中和试验结果显示树鼠血清中存在 EV71 抗体(表 2), 最早出现在感染 EV71 后第 3 天, 其中 静脉注射组中 9 号动物于第 12 天出现最高效价 $1: 16$, 各实验组均有抗体检出, 在攻毒 3 周后仍然 可以检测到中和抗体。 

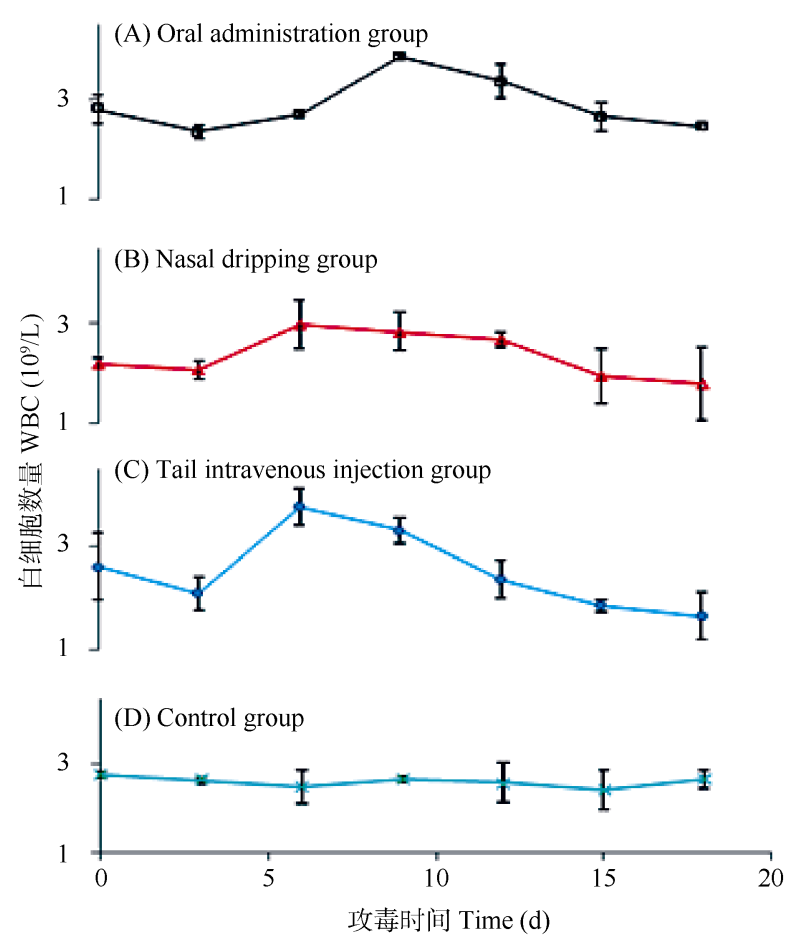

图 3 EV71 感染树舄白细胞变化趋势

Fig. 3 Changes in the WBC of EV71 infected Tupaia belangeri
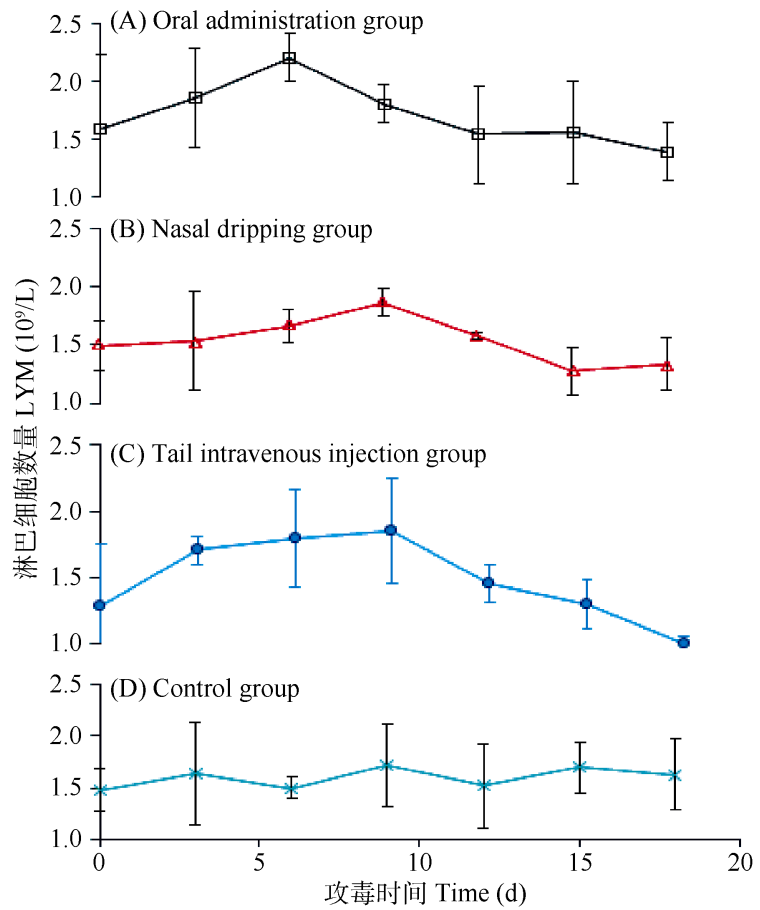

图 4 EV71 感染树鼣淋巴细胞变化趋势

Fig. 4 Changes in the LYM of EV71 infected Tupaia belangeri

表 2 EV71 感染树鼠的中和抗体检测结果

Tab. 2 Neutralizing antibody of EV71 infected in Tupaia belangeri

\begin{tabular}{|c|c|c|c|c|c|c|c|c|c|c|c|c|}
\hline \multirow{2}{*}{$\begin{array}{l}\text { 攻毒天数 } \\
\text { Days }\end{array}$} & \multicolumn{4}{|c|}{$\begin{array}{c}\mathrm{A} \text { 灌胃组 } \\
\text { Oral administration group }\end{array}$} & \multicolumn{4}{|c|}{$\begin{array}{c}\text { B 滴鼻组 } \\
\text { Nasal dripping group }\end{array}$} & \multicolumn{4}{|c|}{$\begin{array}{c}\mathrm{C} \text { 静脉注射组 } \\
\text { Tail intravenous injection group }\end{array}$} \\
\hline & 1 & 2 & 3 & 4 & 5 & 6 & 7 & 8 & 9 & 10 & 11 & 12 \\
\hline $\mathrm{d} 0$ & 0 & 0 & 0 & 0 & 0 & 0 & 0 & 0 & 0 & 0 & 0 & 0 \\
\hline d3 & 0 & 2 & 0 & 0 & 0 & 0 & 0 & 0 & 0 & 0 & 2 & 0 \\
\hline d6 & 0 & 4 & 0 & 2 & 0 & 2 & 4 & 0 & 4 & 2 & 5.6 & 2 \\
\hline d9 & 2 & 2 & 2 & 2 & 0 & 2.8 & 4 & 0 & 4 & 2 & 8 & 0 \\
\hline $\mathrm{d} 12$ & 2 & 2 & 2 & 4 & 2 & 4 & 2 & 2 & 16 & 2 & 4 & 2 \\
\hline $\mathrm{d} 15$ & 0 & 0 & 4 & 2 & 2 & 2 & 0 & 0 & 8 & 0 & 0 & 0 \\
\hline $\mathrm{d} 18$ & 2 & 0 & 0 & 2 & 2 & 2 & 0 & 2 & 4 & 0 & 2 & 0 \\
\hline
\end{tabular}

\section{4 核酸检测}

2.4.1 普通 PCR 检测 EV71 RNA 普通 PCR 产物 大小为 $226 \mathrm{bp}$, 其中血清样品检测到阳性的有灌胃 组 2、3、4 号, 滴鼻组 6 号和静脉注射组的 9、11 号(图 5a); 粪便样品实验组全部检测到阳性(图 5b); 对 4 号树鼠疮疹部位用棉试子取样, 核酸检测到阳 性(图 5c), 其中 0 为阳性对照, (1)、(2)分别检自树鼠 嘴角和脚掌部位。

2.4.2 Real-Time PCR 检测 EV71 RNA 图 6～图9 显示检测血清和粪便样品中的病毒载量变化: 血清 样品灌胃组 2、3、4 号, 滴鼻组 6 号, 静脉注射组 9、
11 号检测到载量变化; 粪便样品各实验组都检测到 病毒载量, 载量变化整体呈先升后降趋势。

\section{5 病理学检查}

组织病理学检查结果(图 10)显示实验组树舀的 脑部出现组织变性坏死、水肿、胶质细胞增生。肺 部出现肺水肿、慢性炎细胞浸润、局部纤维组织增 生等病理变化。心脏出现心肌组织充血、局部间隙 有炎细胞聚集。肠道壁变薄脱落、黏膜上皮细胞缺 损坏死、局部黏膜息肉样增生。脾脏充血、玻璃样 变、脾窦扩张等。肾脏局部皮质充血、肾小球旁有 中性粒细胞浸润。 


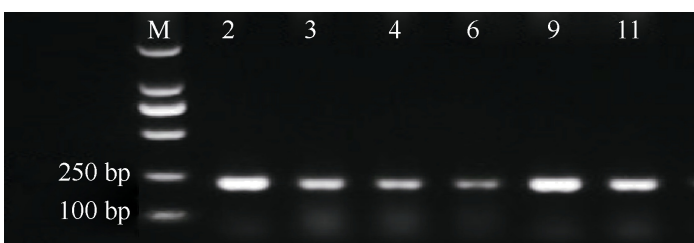

(a)

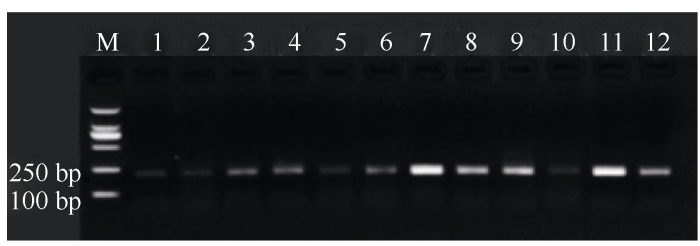

(b)

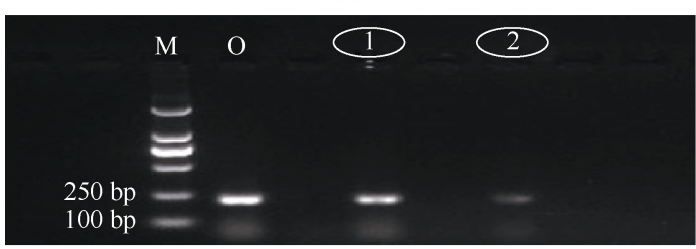

(c)

图 5 感染树䳔 EV71 RNA 的检测

Fig. 5 EV71 RNA of infected Tupaia belangeri a) 血清样品; b) 粪便样品; c) 4 号树鼣疮疹部位试子。

a) Serum; b) Feces; c) Herpes swab from No. 4 Tupaia belangeri.

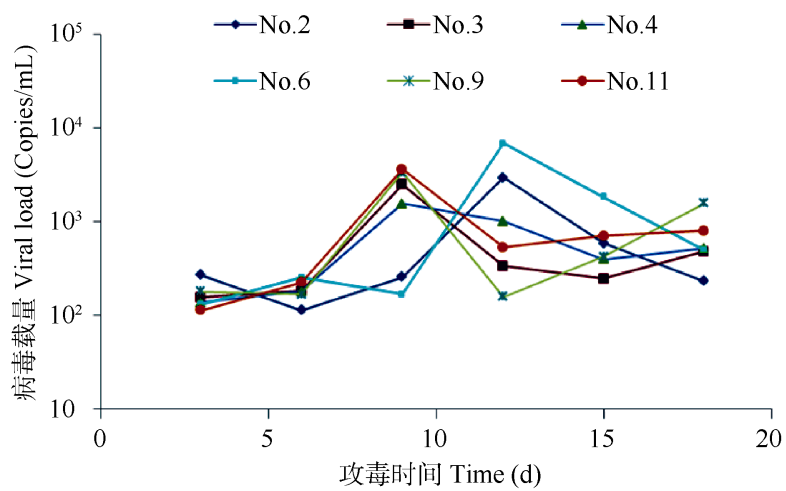

图 6 感染树獡血清中病毒载量的变化

Fig. 6 Changes in the viral load from the serum of EV71 infected Tupaia belangeri

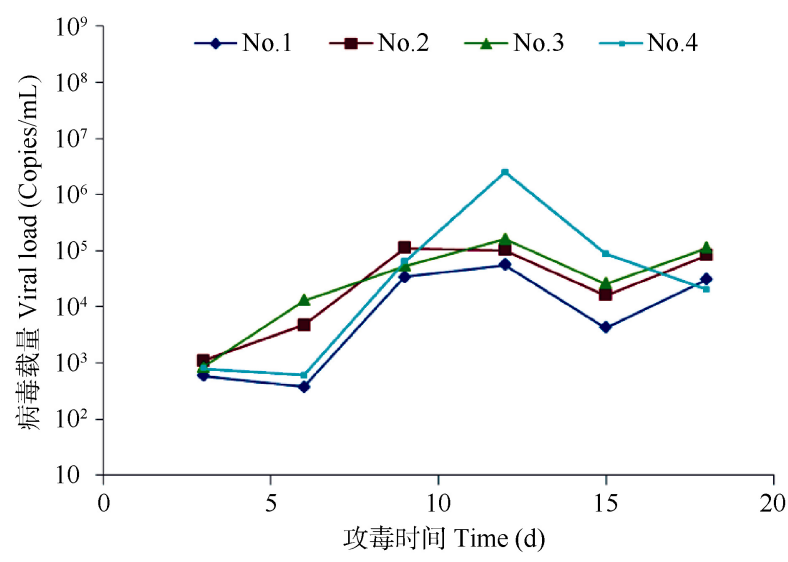

图 7 灌胃 EV71 感染树獡粪便样品载量变化

Fig. 7 Changes in the fecal viral load of EV71 infected Tupaia belangeri (Oral administration group)

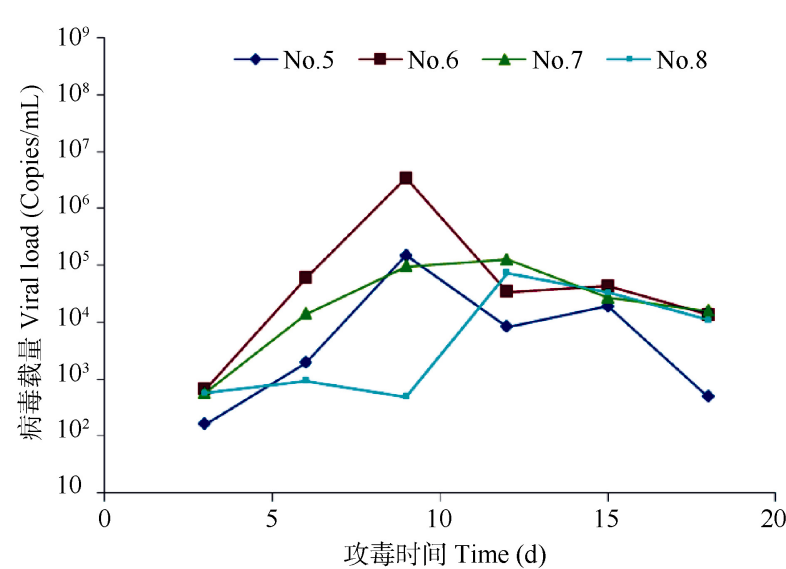

图 8 滴鼻 EV71 感染树鼠粪便样品载量变化

Fig. 8 Changes in the fecal viral load of EV71 infected Tupaia belangeri (Nasal dripping group)

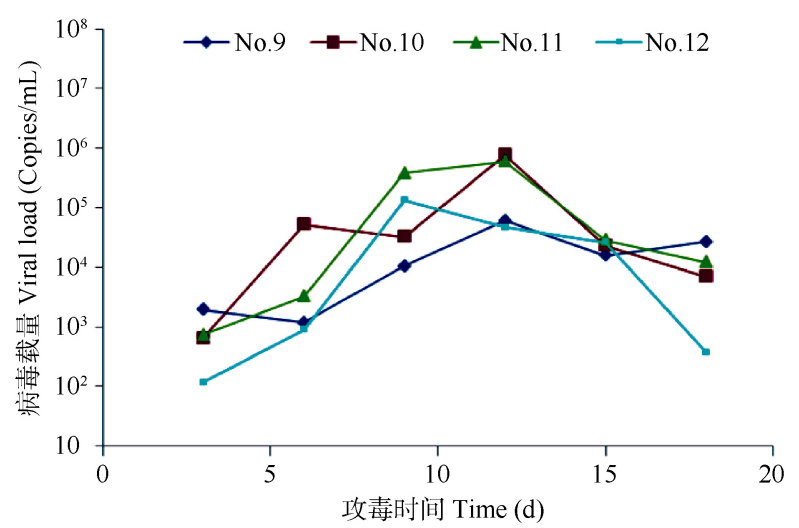

图 9 静脉注射 EV71 感染树鼣粪便样品载量变化

Fig. 9 Changes in the fecal viral load of EV71 infected Tupaia belangeri (Tail intravenous injection group)

\section{3 讨 论}

EV71 危害婴、幼儿健康的关键在于对中枢神 经系统的破坏，继而诱发肺水肿、心肺衰竭等重症， 甚至危及生命。本研究通过 3 种不同途径感染树鼠, 诱发了急性松弛型㿈疾、树鼣活动能力丧失, 精神 低迷、眼眀内陷等症状，与 Chen et al(2004)建立的 EV71 口服感染乳鼠模型症状相吻合; 而 Nagata et al(2002)通过椎管注射方式建立的食蟹猴模型也出 现一系列与人体临床症状相近的神经系统症状, 如 震颤、运动失调、脊髓灰质炎样麻痹等。另外, 我 们通过树鼠大体解剖发现的尿㵔留现象也与一些 EV71 重症患者的临床表现一致。

我们建立的树鼠模型组织病理学检查结果(图 10)显示树鼠的脑部出现组织变性坏死、水肿, 提示 EV71 病毒可能已经侵害树獡的中枢神经系统。

Dong et al(2010)通过静脉注射和呼吸道感染两种途 径建立狝猴模型，也出现类似的中枢神经系统病 

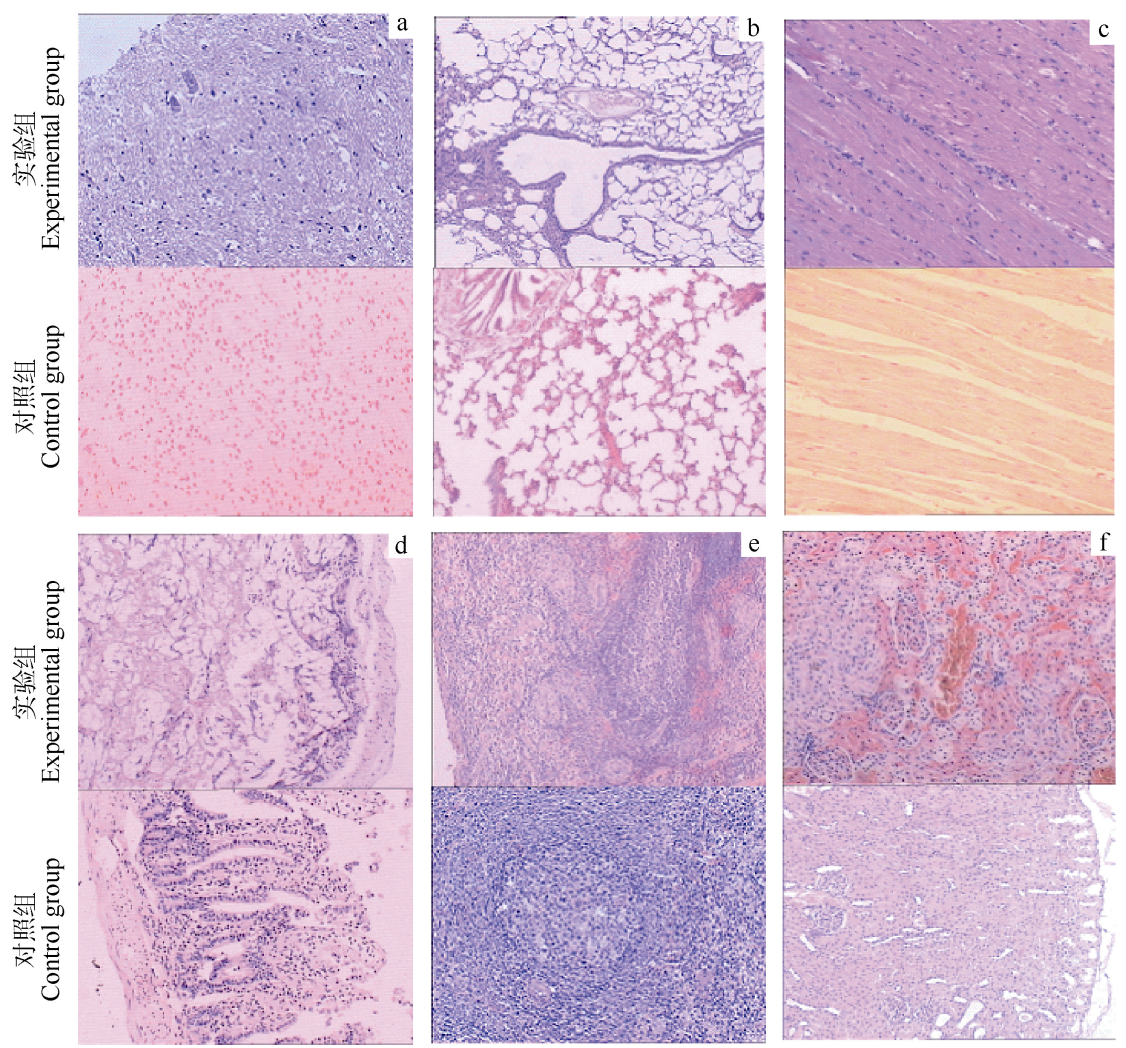

图 10 EV71 感染树鼠的组织病理变化 $(\mathrm{HE}, \times 100)$

Fig. 10 Pathological changes in the tissues of Tupaia belangeri infected with EV71 ( HE, $\times 100)$

a) 脑; b) 肺; c) 心; d) 肠; e) 脾; f) 肾。

a) Brain; b) Lung; c) Heart; d) Intestine; e) Spleen; f) Kidney.

变。我们还发现在实验树鼠肺部出现水肿、慢性炎 细胞浸润、局部纤维组织增生等症状, 这些与 Liu et $\mathrm{al}(2011)$ 的 EV71 型手足口病肺组织病理学研究基本 一致, 支持了 EV71 可引发神经性肺水肿等并发症的 论断(Xu et al, 2008)。实验树鼠心脏出现心肌充血、局 部间隙有炎细胞聚集, 这些变化提示病变树鼠可能 有心脏功能受损。肠道病毒首要侵害部位就是肠道, 本实验中树鼠肠道壁变薄脱落、黏膜上皮细胞缺损 坏死、局部黏膜息肉样增生等症状也恰恰符合了肠 道病毒的感染特性。在实验树鼠的肾脏局部发现皮 质充血、肾小球旁有中性粒细胞浸润。另外, 感染 EV71 的树鼠也出现了与人类似的手足口疮疹。

我们的实验树鼠在感染 EV71 病毒后出现了与 人类似的体温上升现象, 与 Liu et al(2011)建立的贞 猴模型一致。血常规白细胞和淋巴细胞的变化也与 人的病症相符, 在经过一次上升之后开始下降, 并 且有低于正常水平的趋势。中和试验也检测到了抗 体的产生(表 2), 树鼠产生的抗体可以中和 EV71。 本实验结果显示, 部分树鼠在感染 EV71 后 3 周左 右体内仍有抗体存在, 说明树鼠对人的 EV71 毒株 有相当的感染适应性, 可在药物或疫苗评价等研究
中发挥积极有效的作用。另外, 可能由于树鼠个体 差异等因素使得抗体的产生并没有表现一致的规 律性，而中和抗体效价比乳鼠模型较低(Arita et al, 2007), 可能是物种差异等所致。从免疫学角度来看, 如果制备树鼠专用的 ELISA 检测试剂盒, 将会丰富 检测指标和提高检测效率。我们主要采用分子生物 学手段检测树鼠感染病毒的状况, 其中 Real-time PCR 可以精确检测病毒在树鼠体内的载量变化, 可 以看出病毒在树鼣体内复制 $10 \mathrm{~d}$ 前后出现峰值, 之 后有所下降。树鼠 2 周前后发病, 重病者 $18 \mathrm{~d}$ 左右 死亡, 从感染病毒到发病的时间与㚣猴模型(Liu et al, 2011)比较接近。总的看来, 以上的这一整套检测方 案切实可行, 这为树鼠模型的建立评价奠定了基础。

EV71 作为肠道病毒自然感染途径有消化道和 呼吸道(Chen et al, 2010)。在动物建模方法上，先后 有人经由口服和鼻腔途径成功感染小鼠(Lin et al, 2009)、猕猴(Liu et al, 2011)。本研究将 EV71 通过 灌胃、滴鼻和静脉注射 3 种途径感染树鼣, 在血液 和粪便样品中均检测到病毒载量。静脉注射在很多 病毒感染中都可以普遍实现，但非自然感染途径; 而滴鼻和灌胃更符合 EV71 自然感染的特点, 其中 
灌胃略胜一筹, 感染方法证实可行。我们的实验结 果证实, 树鼠可通过灌胃或滴鼻等自然感染途径来 建立其动物模型。本实验发病树鼠的临床表现、感 染周期以及病理病变等感染特性说明, 树鼠模型比 小鼠模型更接近人的发病情况, 而与狝猴动物模型 相比，树鼠具有体型小、实验周期短、便于饲养管 理且成本低廉等优越性, 可望替代灵长类动物用于 人类手足口疾病的发生、发展机理及预防和治疗的 研究。本次试验半数动物最终发病死亡, 提示需要 研究攻毒最适剂量。另外, 我们还将研究不同年龄 树舄的感染能力, 从而找到最适年龄的树鼣做模型 研究。如果能从树鼠体内不同器官组织分离并鉴定 出病毒, 继而进行传代感染适应, 通过人工繁殖技 术培育对 EV71 敏感的携带病毒的树鼠种群, 将对 开展手足口疾病的动物模型建立、药物笁选和疫苗 评价具有长远的科学意义和应用价值。

通过本研究, 我们成功建立了中缅树鼠感染 EV71 的动物模型。通过对该动物模型的系统研究, 我们拟定了 EV71 感染中缅树鼠动物模型的评价指
标: 1)动物临床表现: 潜伏期一般 $5 \mathrm{~d}$ 左右。体温升 高, 活动减少, 饮食下降, 粪便稀黑; 树鼠嘴脚部位 可见疮疹, 重症出现急性松弛型㿈疾, 或伴有尿㵔 留, 部分急症可致死亡。2)实验室检测结果: 血常规 可见白细胞、淋巴细胞水平升高, 血清中可检测到 抗 EV71 中和抗体, 血清和粪便中可检测到病毒核 酸, rReal-time PCR 可监测血液、粪便等样品中病毒 载量变化。3)病理学变化: 可见心、脑、肺、肠、肾、 脾等部位病变, 如表现有脑组织坏死、水肿, 肺水 肿、炎细胞浸润，心肌充血、伴有炎症，肠壁脱落、 黏膜上皮细胞坏死，肾脾充血炎症等。我们的这些研 究成果相信将为以后建立成熟的 EV71 动物模型提 供科学依据, 为深入了解 EV71 的致病机理和开发有 效的药物疫苗构建科研平台，同时这对树鼣资源在 生物医学领域的开发应用也具有很大的现实意义。

致谢: 感谢医学生物学研究所病毒免疫室赵树 栋等老师提供 EV71 病毒株以及在病毒培养技术方 面给予的帮助。

\section{参考文献:}

Arita M, Nagata N, Iwata N, Ami Y, Suzaki Y, Mizuta K, Iwasaki T, Sata T, Wakita T, Shimizu H. 2007. An attenuated strain of enterovirus 71 belonging to genotype ashowed a broad spectrum of antigenicity with attenuated neurovirulence in cynomolgus monkeys[J]. J Virol, 81(17): 9386-9395.

Chen GQ, Shao RB, Wang HY, Chen YH. 2010. Research progress on pathogen and pathogenic molecular mechanisms of enterovirus $71[\mathrm{~J}]$. Prog Mod Biomed, 10(19): 3795-3797. [陈国清，邵荣标，王海燕，陈 玉宏. 2010. 肠道病毒 EV71 病原学以及致病分子机制的研究进展. 现代生物医学进展, 10(19): 3795-3797.]

Chen YC, Yu CK, Wang YF, Liu CC, Su IJ, Lei HY. 2004. A murine oral enterovirus 71 infection model with central nervous system involvement[J]. J Gen Virol, 85(1): 69-77.

Dong C, Wang J, Liu L, Zhao H, Shi H, Zhang Y, Jiang L, Li Q. 2010. Optimized development of a candidate strain of inactivated EV71 vaccine and analysis of its immunogenicity in rhesus monkeys[J]. Hum Vaccin, 6(12): 1028-37.

Duo JY, Wang W, Tong W, Cong Z, Jiang H, Xu WB, Wei Q, Qin C. 2009. Experimental studies on ICR mice with EV71 infection[J]. Chn $J$ CompMed, 19(5): 41-46. [朵建英, 王卫, 佟巍, 从喆, 蒋虹, 许文波, 魏强, 秦川. 2009. 肠道病毒 71 型(EV71)对 ICR 小鼠的感染. 中国 比较医学杂志, 19(5): 41-46.]

Lin YW, Chang KC, Kao CM, et al. Chang SP, Tung YY, Chen SH. 2009. Lymphocyte and antibody responses reduce enterovirus 71 lethality in mice by decreasing tissue viral loads[J]. J Virol, 83(13): 6477-6483.

Liu LD, Zhao HL, Zhang Y, Wang JJ, Che YC, Dong CH, Zhang XM, Na RX, Shi HJ, Jiang L, Wang LC, Xie ZP, Cui PF, Xiong XL, Liao Y, Zhao SD, Gao JH, Tang DH, Li QH. 2011. Neonatal rhesus monkey is a potential animal model for studying pathogenesis of EV71 infection[J]. Virology, 412(1): 91-100.

Liu WW, Liu ZJ, Wang X, Cui W. 2011. The pathology study of lung in hand, foot and mouth disease which is caused by enterovirus $71[\mathrm{~J}] . J$

Jining Med College, 34(2): 93-95. [刘伟伟, 刘增甲, 王旭, 崔文. 2011. EV71 型手足口病肺组织病理学研究. 济宁医学院学报, 34(2): 93-95.]

Mao QY, He P, Yu X, Li N, Hao CS, Gao Q, Dong CH, Liang ZR, Li FX, Shen XL, Wang ZJ. 2010. Laboratory evaluation of method for determination of neutralizing antibody against human enterovirus $71[\mathrm{~J}]$. Chn J Biol, 23(8): 885-888. [毛群颖, 何鹏, 于祥, 李楠, 郝春生, 高 强, 董承红, 梁争论, 李凤翔, 沈心亮, 王军志. 2010 . 人肠道病毒 71 型中和抗体检测方法的实验室评价. 中国生物制品学杂志, 23(8): 885-888.]

Nagata N, Iwasaki T, Ami Y, Tano Y, Harashima A, Suzaki Y, Sato Y, Hasegawa H, Sata T, Miyamura T, Shimizu H. 2004. Differential localization of neurons susceptible to enterovirus 71 and poliovirus type 1 in the central nervous system of cynomolgus monkeys after intravenous inoculation[J]. J Gen Virol, 85(10): 2981-2989.

Nagata N, Shimizu H, Ami Y, Tano Y, Harashima A, Suzaki Y, Sato Y, Miyamura T, Sata T, Iwasaki T. 2002. Pyramidal and extrapyramidal involvement in experimental infection of cynomolgus monkeys with enterovirus 71[J]. J Med Virol, 67(2): 207-216.

Sargis EJ. 2004. New views on tree shrews: the role of tupaiids in primate supraordinal relationships[J]. Evol Anthropol, 13(2): 56-66.

Xu RF, Li TT, Feng XY, Zhang H, Song B, Liu C, Xu L. 2008. Therapeutic effect of hyper oxygenated solution on acute lung injury induced by oleic acid[J]. Eur Surg Res, 41(1): 37-43.

Wang XJ, Yang C, Su JJ. 2010. Development of application of tree shrew in experimental medical research[J]. Chn J Comp Med, 20(2): 67-70. [王 晓娟, 杨春, 苏建家. 树鼣在医学实验研究中的新进展. 中国比较 医学杂志, 20(2): 67-70.]

Wang XX, Li JX, Wang WG, Sun XM, He CY, Dai JJ. 2011. Preliminary investigation of viruses to the wild tree shrews[J]. Zool Res, 32(1): 66-69. [王新兴, 李婧潇, 王文广, 孙晓梅, 何春艳, 代解杰. 2011 . 野生中缅鼣病毒携带情况的初步调查. 动物学研究, 32(1): 66-69.] 